\title{
Aplicación de microorganismos benéficos para la producción de flor de cempasúchil (Tagetes erecta)
}

\section{Application of beneficial microorganisms for the producction of Mexican marigold flower (Tagetes erecta)}

\author{
GÓMEZ-LUNA, Blanca Estela*†, VELOZ-GARCÍA, Rafael Alejandro, DÍAZ-PÉREZ, César y \\ RAMÍREZ-GRANADOS, Juan Carlos
}

Universidad de Guanajuato, Campus Celaya-Salvatierra, Departamento de Ingeniería Agroindustrial,

ID $1^{\text {er }}$ Autor: Blanca Estela, Gómez-Luna / ORC ID: 0000-0001-6345-046, CVU CONACYT ID: 101592

ID $1^{\text {er }}$ Coautor: Rafael Alejandro, Veloz-García / ORC ID: 0000-0002-6493-5708, Researcher ID Thomson: S-5809-2018, CVU CONACYT ID: 163099

\author{
ID 2 $2^{\text {do }}$ Coautor: César, Díaz-Pérez / ORC ID: 0000-0001-7847-1062, Researcher ID Thomson: X-5157-2019, CVU \\ CONACYT ID: 101579
}

ID $3^{\text {er }}$ Coautor: Juan Carlos, Ramírez-Granados / ORC ID: 0000-0001-6460-6472, Researcher ID Thomson: S-5874-2018, CVU CONACYT ID: 167866

DOI: $10.35429 /$ JSI.2019.9.3.1.4

Recibido 02 de Enero, 2019; Aceptado 30 de Marzo, 2019

\section{Resumen}

El cempasúchil (Tagetes erecta) es una planta originaria de México, los usos son: pigmentos, saborizante, perfumería, ornamental, insecticidas, nematicidas y medicinal. En el suelo existe una gran riqueza de microorganismos hongos formadores de micorriza y rizobacterias promotoras de crecimiento vegetal con un papel importante en los procesos que afectan la transformación de nutrientes en el suelo y su disponibilidad para las plantas y protección contra microorganismos fitopatógenos. El objetivo de este trabajo fue evaluar el efecto del uso de microorganismos benéficos en el desarrollo de la flor de cempasúchil comparado con la aplicación de un fertilizante. Las cepas bacterianas fueron identificadas como 225, 254, 302 y un inóculo de hongos micorrícicos. El fertilizante Blue Garden. Se determino peso fresco, peso seco, cantidad de flores, tamaño de la raíz. Se utilizó un diseño experimental completamente al azar y prueba de Tukey. De acuerdo con los resultados obtenidos los mejores tratamientos que pueden tener un uso potencial fueron los siguientes tratamientos: fertilizante, cepa 254, cepa 302 y cepa 254 y micorriza. El uso de microorganismos benéficos para producción de plantas de cempasúchil mostró ser efectivo y comparable con aplicación de fertilizante, por lo tanto, reducir su uso e incluso eliminarlo.

\begin{abstract}
The Mexican marigold flower (Tagetes erecta) is a plant native to Mexico, the uses are: pigments, flavoring, perfumery, ornamental, insecticides, nematicides and medicinal. In the soil there is a great richness of microorganisms mycorrhizal fungi and plant growth promoting rhizobacteria with an important role in the processes that affect the transformation of nutrients in the soil and their availability for plants and protection against phytopathogenic microorganisms. The objective of this work was to evaluate the effect of the use of beneficial microorganisms in the development of the cempasúchil flower compared with the application of a fertilizer. The bacterial strains were identified as 225, 254, 302 and an inoculum of mycorrhizal fungi. The Blue Garden fertilizer. Fresh weight, dry weight, number of flowers, root size were determined. A completely randomized experimental design and Tukey test were used. According to the results obtained, the best treatments that could have a potential use were the following treatments: fertilizer, strain 254, strain 302 and strain 254 and mycorrhiza. The use of beneficial microorganisms for the production of Mexican marigold flowers was shown to be effective and comparable with the application of fertilizer, therefore reducing its use and even eliminating it.
\end{abstract}

Soil, Rhizobacteria, Mexican marigold flower 


\section{Introducción}

Las plantas del género Tagetes son herbácea anual o perennes, erecta y muy aromáticas, de tallos estriados y hojas pinadas, cuya flor una cabezuela solitaria conocida como capítulo, inflorescencia que a su vez contiene numerosas flores individuales de los tipos tubulares o ligulares (Serrato-Cruz, 2006).

El género Tagetes (Tageteae; Asteraceae) se compone de alrededor de 55 especies distribuidas principalmente en el continente americano, la mayoría de las cuáles se localizan en México (Turner y Nesom,1993). Los usos potenciales de las plantas de Tagetes spp son numerosos: antioxidante en células humanas, pigmento de alimentos, saborizante, perfumería, resina, ornamental, alteración genética con fines de control de malezas, insecticida, nematicida, larvicida, atrayente ó repelente de insectos, abono verde y medicinal.

De Tagetes erecta destacan las inflorescencias de gran tamaño que se producen en los valles de México y de Oaxaca, Valles de CuautlaCuernavaca, Valle de Huejotzingo, Valle de Teotihuacán y la Región del Bajío. Plantas con múltiples inflorescencias, hasta 120, pero de tamaño pequeño se localizan en la región de la Huasteca y en la región de Chatina, Oaxaca.

En las Huastecas se pueden observar coloraciones de inflorescencias amarillo pálido, casi blanco; mientras que las flores con colores anaranjados intensos pueden encontrarse en el Bajío, en Xochimilco estado de México y en Pátzcuaro, Michoacán; entre otros lugares (Serrato Cruz, 2004). En cuanto a la intensidad del color de la flor, los tonos más intensos del color anaranjado de las inflorescencias de $\mathrm{T}$. erecta están relacionados con un mayor contenido de carotenoides, su gran diversidad de tonalidades potencializa el aprovechamiento que se puede hacer de este pigmento (RincónEnríquez y col., 2012).

En el suelo existe una gran riqueza de microorganismos entre estos destacan hongos formadores de micorriza, bacterias, controladores de plagas y Enfermedades (antagónicos), y rizobacterias promotoras de crecimiento vegetal PGPR (por sus siglas en inglés).
Estos microorganismos juegan un papel importante en los procesos que afectan la transformación de una gran variedad de nutrientes en el suelo y su disponibilidad para las plantas. Además, el uso permanente de fertilizantes químicos es un costo significativo para la agricultura a nivel mundial. Por tal motivo, el uso de microorganismos como inoculantes para movilizar fuentes de nutrientes pobremente disponibles en el suelo, es una alternativa para reducir la contaminación ambiental y mejorar la productividad de los cultivos.

Las bacterias promueven el crecimiento y desarrollo de las plantas, mejoran la capacidad de fijación de nitrógeno, la sanidad vegetal, a través del control biológico de fitopatógenos, la disponibilidad de minerales y nutrientes en el suelo, disminuyen la susceptibilidad a las heladas, inducen en las plantas la resistencia sistémica a las enfermedades y facilitan el establecimiento de plantas.

Las rizobacterias promotoras del crecimiento de plantas son un grupo de bacterias que habitan en la raíz de las plantas y suelo adherido a ésta, este espacio es conocido como rizósfera (Cassán et al., 2009). En la rizósfera se producen una variedad de ácidos orgánicos que pueden ser metabolizados por las rizobacterias. Las rizobacterias a su vez proporcionan nutrientes del suelo a la planta (Marschner, et al., 2004; Lugtenberg y Kamilova, 2009).

Las plantas con micorrizas pueden captar más agua, absorber más nutrimentos, incrementar la vida útil de las raíces absorbentes, mejorar la absorción iónica, solubilizar minerales que se encuentran en el suelo, aumentar la capacidad fotosintética de la planta, incrementarla resistencia de raíces a infecciones causadas por patógenos, además del incremento de la tolerancia de las plantas a toxinas del suelo, disminuyendo el estrés causado por factores ambientales y presentar mayor tolerancia a sequía, cambios de temperatura y algunos patógenos.

El fertilizante ayuda aquel rendimiento de los cultivos se duplique, reduce la erosión, normaliza la temperatura de la superficie y ayuda a almacenar más humedad, esto es bueno cuando las lluvias son escasas. 
Partiendo de lo anterior, en este estudio se evaluó el efecto del uso de microorganismos benéficos como bacterias de las cepas 225, 254 y 302 , micorriza y fertilizante en el desarrollo de la flor de cempasúchil (Tagetes erecta).

\section{Materiales y métodos}

Material biológico. Las bacterias utilizadas son de la colección de rizobacterias del laboratorio de biotecnología de investigación Universidad de Guanajuato. Las cepas bacterianas fueron identificadas como 225, 254 y 302. Todas son rizobacterias con forma de bacilo gram positivas.

El inoculo de micorriza fue donada del Instituto Nacional de Investigaciones Forestales, Agropecuarias y Pecuarias (INIFAP). El fertilizante empleado fue de la marca Blue Garden, es un fertilizante granulado, especialmente diseñado para la etapa de desarrollo y maduración de frutos por su aporte balanceado de nitrógeno y potasio, complementado con fósforo y microelementos necesarios para el cultivo.

Se utilizaron 45 plantas de cempasúchil, en nueve tratamientos. Los tratamientos consistieron en: 1) Control (sin ningún microorganismo), 2) Control con fertilizante, 3) Inoculado con la bacteria de la cepa 225,4 ) Inoculado con la bacteria 302, 5) Inoculado con la bacteria 254, 6) Con micorriza, 7) Inoculado con la bacteria 225 y micorriza, 8) Inoculado con la bacteria 302 y micorriza y 9) Inoculado con la bacteria 254 y micorriza. El sustrato en todos los casos fue peat moss estéril. El experimento se realizó en cinco meses de julio a noviembre de 2018.

\section{Análisis estadístico}

Se realizó un análisis de varianza de tipo ANOVA utilizando la prueba de Fisher con un valor de $\alpha$ igual 0.05 , además de una comparación de medias con un $\alpha$ igual 0.05 con la prueba de Tukey.

\section{Resultados}

Con los resultados presentados en la tabla1, podemos observar las medias de los tratamientos en diferentes parámetros y que existen diferencias estadísticamente significativas entre ellos.

\begin{tabular}{|c|cc|r|r|r|r|}
\hline & $\begin{array}{c}\text { Peso } \\
\text { Fresco } \\
\text { Raíz }[\mathrm{c}]\end{array}$ & $\begin{array}{c}\text { Preso } \\
\text { Féreo }[g]\end{array}$ & \multicolumn{1}{c}{$\begin{array}{c}\text { Peso } \\
\text { Fresco } \\
\text { Total }[g]\end{array}$} & $\begin{array}{c}\text { Peso } \\
\text { Seco } \\
\text { Raíz }[g]\end{array}$ & $\begin{array}{c}\text { Peso } \\
\text { Seco } \\
\text { aéreo }[g]\end{array}$ & $\begin{array}{c}\text { Peso Seco } \\
\text { Total }[g]\end{array}$ \\
\hline T1 & $20.31 \mathrm{a}$ & $43.93 \mathrm{a}$ & $64.16 \mathrm{a}$ & $3.16 \mathrm{a}$ & $10.99 \mathrm{a}$ & $14.02 \mathrm{a}$ \\
\hline T2 & $29.13 \mathrm{a}$ & $47.18 \mathrm{a}$ & $75.84 \mathrm{a}$ & $4.47 \mathrm{a}$ & $12.37 \mathrm{a}$ & $16.85 \mathrm{a}$ \\
\hline T3 & $21.72 \mathrm{a}$ & $33.64 \mathrm{a}$ & $55.08 \mathrm{a}$ & $2.99 \mathrm{a}$ & $8.09 \mathrm{a}$ & $11.05 \mathrm{a}$ \\
\hline T4 & $3.69 \mathrm{~b}$ & $20.55 \mathrm{~b}$ & $24.15 \mathrm{~b}$ & $2.47 \mathrm{a}$ & $8.30 \mathrm{a}$ & $10.73 \mathrm{a}$ \\
\hline T5 & $16.36 \mathrm{a}$ & $36.05 \mathrm{a}$ & $52.08 \mathrm{a}$ & $2.26 \mathrm{a}$ & $7.52 \mathrm{a}$ & $9.59 \mathrm{a}$ \\
\hline T6 & $16.45 \mathrm{a}$ & $35.44 \mathrm{a}$ & $51.71 \mathrm{a}$ & $2.36 \mathrm{a}$ & $7.71 \mathrm{a}$ & $10.06 \mathrm{a}$ \\
\hline T7 & $7.28 \mathrm{a}$ & $22.87 \mathrm{~b}$ & $31.88 \mathrm{~b}$ & $1.42 \mathrm{a}$ & $5.14 \mathrm{~b}$ & $6.91 \mathrm{~b}$ \\
\hline T8 & $26.29 \mathrm{a}$ & $38.60 \mathrm{a}$ & $64.68 \mathrm{a}$ & $3.77 \mathrm{a}$ & $8.22 \mathrm{a}$ & $12.15 \mathrm{a}$ \\
\hline T9 & $31.48 \mathrm{a}$ & $56.54 \mathrm{a}$ & $91.78 \mathrm{a}$ & $5.21 \mathrm{a}$ & $11.57 \mathrm{a}$ & $17.03 \mathrm{a}$ \\
\hline
\end{tabular}

Tabla 1 Efecto de microorganismos benéficos en el crecimiento de la flor de cempasúchil. Las letras iguales no tienen diferencias significativas con un $\alpha$ igual0.05 con la prueba de Tukey

\begin{tabular}{|c|c|c|}
\hline & Flores & Raíz [cm] \\
\hline T1 & $8 a$ & $26.20 \mathrm{a}$ \\
\hline T2 & $9 \mathrm{a}$ & $29.82 \mathrm{a}$ \\
\hline T3 & $6 a$ & $26.98 \mathrm{a}$ \\
\hline T4 & $7 \mathrm{a}$ & $26.02 \mathrm{a}$ \\
\hline T5 & $9 \mathrm{a}$ & $36.94 a$ \\
\hline T6 & $8 \mathrm{a}$ & $20.20 \mathrm{a}$ \\
\hline T7 & $6 \mathrm{a}$ & $18.8 \mathrm{a}$ \\
\hline T8 & $9 \mathrm{a}$ & $25.6 a$ \\
\hline T9 & $11 \mathrm{a}$ & $22.74 a$ \\
\hline
\end{tabular}

Tabla 1 (continuación). Efecto de microorganismos benéficos en el crecimiento de la flor de cempasúchil. Las letras iguales no tienen diferencias significativas con un $\alpha$ igual0.05 con la prueba de Tukey

También podemos observar que el tratamiento 9 (Micorriza + Bacteria 254) es el que tiene mayor peso fresco (raíz, parte aérea y total), así mismo en el peso seco (raíz, parte aérea y total) y la cantidad de flores. Este tratamiento es conveniente para la producción de biomasa. El tratamiento 2 (Fertilizante Blue Garden) también tiene buen resultado respecto al peso fresco, peso seco, pero también en el tamaño de la raíz y número de hojas ocupando el segundo lugar en cuanto a los dos últimos casos.

El tratamiento 8 (Micorriza+ Bacteria 302) es el mejor tratamiento para el número de hojas, ocupa el tercer lugar en peso fresco (raíz, total), peso seco de la raíz, y el segundo en cuanto a flores.

El tratamiento 5 (Bacteria 254) tiene una producción de flores buena al igual que el tamaño de la raíz, el tratamiento3 (Bacteria 225) también tiene un tamaño de raíz superior que al control. En cuanto a la longitud del tallo respecto al tiempo el tratamiento 6 (Micorriza) es mejor. 


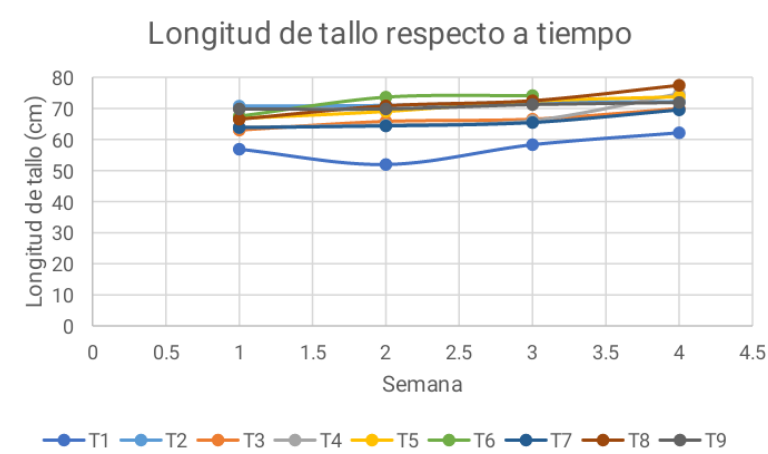

Gráfico 1 Efecto de los microorganismos benéficos en la longitud de tallo de flor de cempasúchil.

En el Gráfico 1, se representa el promedio de cada tratamiento en un intervalo de 4 semanas, usando la prueba de Fisher con 0.05 y observamos que existen diferencias significativas entre los tratamientos. Siendo el mejor en este parámetro el tratamiento 6 .
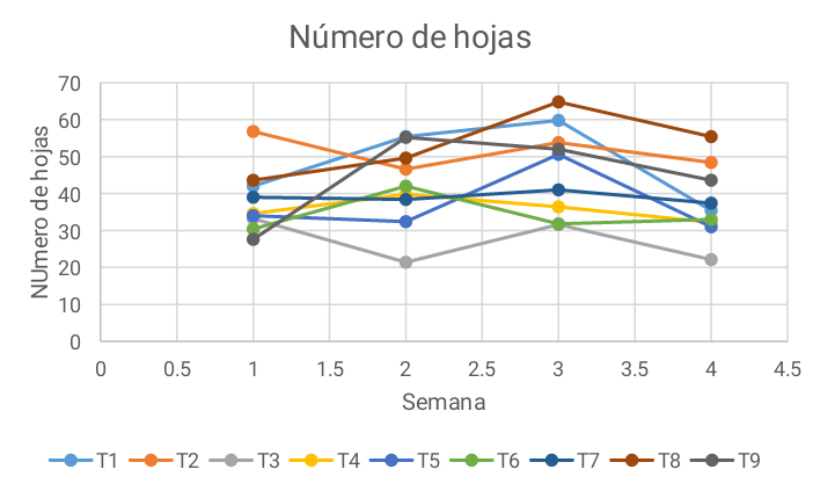

Gráfico 2 Efecto de los microorganismos benéficos en la producción de hojas en flor de cempasúchil.

En el Gráfico 2, se representa el promedio de cada tratamiento en un intervalo de 4 semanas, usando la prueba de Fisher con 0.05 y observamos que existen diferencias altamente significativas entre los tratamientos. Siendo el mejor en este parámetro el tratamiento 8 .

\section{Conclusiones}

El uso de microorganismos benéficos en las plantas de cempasúchil nos deja ver que algunos de los tratamientos tienen un uso potencial, entre ellos se encuentra el tratamiento 9 es mejor para la producción de biomasa vegetal, se puede utilizar para extraer abono orgánico para la tierra de cultivo, de esta forma mejorar la calidad del suelo. También se pueden aplicar extractos acuosos y polvos de diferentes partes de la planta (raíces, tallos y hojas, o toda la planta) para repeler o matar insectos en cultivos o para granos almacenados.
El tratamiento 8 resulto resistente al estrés hídrico. El tratamiento 5 por la cantidad de flores se podría extraer los pigmentos para la elaboración de harina y utilizarse como aditivos en la elaboración de alimentos para aves, peces y crustáceos.

\section{Referencias}

Cassán, F., Perrig, D., Sgroy, V., Masciarelli, O., Penna, C. \& Luna, V. (2009). Azospirillum brasilense Az39 and Bradyrhizobium japonicum E109, inoculated singly or in combination, promote seed germination and early seedling growth in corn (Zea mays L.) and soybean (Glycine $\max$ L.). European Journal of Soil Biology, 45(1), 28 - 35.

Lugtenberg, B. \& Kamilova, F. (2009). PlantGrowth-Promoting Rhizobacteria. Annual Review of Microbiology. 63:541 - 566.

Marschner, P., Crowley, D.E. \& Yang C.H. (2004). Development of specific rhizosphere bacterial communities in relation to plant species, nutrition and soil type. Plant and Soil, 261: $199-208$.

Serrato-Cruz, M.A. (2004). Cempoalxóchilt: diversidad biológica y usos. Ciencia $\mathrm{Y}$ Desarrollo En Internet, Julio-Agosto.

Serrato-Cruz, M.A. (2006). Manual grafico para la descripción varietal de cempasúchil (Tagetes). SNICS-SAGARPA y UACh, México. 100 pp.

Rincón-Enríquez G., E. E. Quiñones-Aguilar, J. A. Qui-Zapata y M. A. Serrato Cruz. (2012). Efectividad biológica de extractos de Tagetes spp sobre bacterias fitopatógenas. SNICSSINAREFI, CIATEJ, México.

Turner, B.L. any G.L. Nesom. (1993). Biogeography, diversity, and endangered or threatened status of Mexican Asteraceae. In: Biological Diversity of Mexico: Origins and Distribution. Ramamoorty, T. P., R. Bye, A. Lot, and J. Fa (eds.). Oxford University Press. New York, USA. pp: 290-299. 